\title{
Psychological profiles of patients with multiple sclerosis based on Hobfoll's conservation of resources theory
}

\section{BACKGROUND}

The psychological perspective plays a crucial role in designing therapy for people suffering from multiple sclerosis. The aim of the article is to distinguish different psychological profiles of patients.

\section{PARTICIPANTS AND PROCEDURE}

The study was conducted using the paper-and-pencil method on 77 patients suffering from multiple sclerosis. The theory we applied was Hobfoll's conservation of resources theory. We also analyzed the impact of personal and situational variables on the functioning of patients with different kinds of resources.

\section{RESULTS}

Cluster analysis was used to construct the profiles of patients. Based on statistical analyses using the $k$-means method, we distinguished: Profile 1, with a prevalence of resource losses $(n=30)$, Profile 2, covering people who value their resources the most $(n=25)$, and Profile 3, with a prevalence of resource gains $(n=18)$.

CONCLUSIONS

The obtained psychological profiles reflect the varied dynamics of the patients' functioning and should inspire an improvement of multidisciplinary rehabilitation.

\section{KEY WORDS}

resources; multiple sclerosis; psychological profiles

ORganization - Department of Health Psychology and Clinical Psychology, Institute of Psychology, Adam Mickiewicz University in Poznan, Poland

aUthors' Contributions - A: Study design - B: Data collection - C: Statistical analysis - D: Data interpretation .

E: Manuscript preparation · F: Literature search · G: Funds collection

CORResponding AUthor - Natalia Nowaczyk, Department of Health Psychology and Clinical Psychology, Institute of Psychology, Adam Mickiewicz University in Poznan, 89 Szamarzewskiego Str., 60-568 Poznan, Poland, e-mail: natalianowaczyk_nn@wp.pl

TO CITE THIS ARTICLE - Nowaczyk, N., \& Cierpiałkowska, L. (2016). Psychological profiles of patients with multiple sclerosis based on Hobfoll's conservation of resources theory. Health Psychology Report, 4(4), 332-339. doi: $10.5114 /$ hpr.2016.59990 


\section{BACKGROUND}

As a result of the demyelination process in various locations in the brain and the spinal cord, people with multiple sclerosis exhibit a broad spectrum of somatic, physiological, and psychological symptoms. Apart from nonspecific symptoms, associated with the very process of suffering from disease and undergoing therapeutic procedures, more specific ones also occur. For this reason, patients with multiple sclerosis do not make a homogeneous group, and their psychological profiles seem to be fairly diverse. Resources related to many different life domains have been recognized as crucial in explaining the patients' psychological portrait, particularly from the perspective of improving their rehabilitation (Khan, McPhail, Brand, Turner-Stokes, \& Kilpatrick, 2006). The aim of the research presented below was to distinguish and describe different profiles of the resources of patients suffering from multiple sclerosis and to identify the personal and situational factors that underlie them.

Conservation of resources involves striving to obtain, maintain, and preserve what is the most valuable to the individual (Hobfoll, 2012), and in a situation of experiencing a disease whose course is unpredictable and when prognosis is uncertain a severe loss in resources is likely to occur. In the present study, the following resources were recognized as important: a) family resources, referring to support from and relations with the family; b) vital resources, connected with an active attitude to life; c) spiritual resources, concerning hope, religion, and personal development; d) economic and political resources, relating to the patient's socioeconomic status; and e) power and prestige resources, relating to the need for dominance and career management (Gruszczyńska, 2012). The concept of resources is broad enough to cover nearly every factor that can positively influence human behavior. The assessment of the patient's resources and knowledge about their determinants seem to be very helpful and important in the process of providing psychological assistance as well as in maintaining health and well-being during illness.

The functioning of patients with multiple sclerosis has not been analyzed from the perspective of the conservation of resources theory yet, but attempts have been made to define patients' profile in the general sense and with reference to specific symptoms, such as fatigue (Schreiber, Lang, Kiltz, \& Lang, 2015) or depression (Ožura \& Sega, 2013). What is also important is a reliable analysis of the strategy of coping with the disease, which explains patients' behavior in the face of the disease and points to the importance of maintaining constant activity (Milanlioglu et al., 2014). Also other studies show that people with multiple sclerosis differ from one another in terms of the strategies of coping with illness and treatment
(Nowaczyk \& Cierpiałkowska, 2016). It therefore seems that it is precisely the resources the patient possesses that are the key indicator making it possible to understand the functioning of a person entangled in the unpredictability of multiple sclerosis.

\section{PARTICIPANTS AND PROCEDURE}

\section{MEASURES}

The study was carried out using the paper-and-pencil method. We used a demographic data survey as well as Polish versions of questionnaires and scales measuring the variables analyzed: coping strategies (the Proactive Coping Inventory by Greenglas et al. as adapted into Polish by Sęk, Pasikowski, Taubert, Greenglas, and Schwarzer, 2002), subjectively perceived social support (Barrera's Inventory of Socially Supportive Behaviors as adapted into Polish by Sęk, 1991), depressive experience (the Depressive Experience Questionnaire by Blatt, D'Aflitti, and Quinlan, translated into Polish by Czeszkiewicz, 2014), positive and negative experience (the Scale of Positive and Negative Experience by Ed Diener and Robert Bitwas-Diener - currently being adapted by Kaczmarek and Baran), the sense of fatigue, and pain complaints (own scales).

Conservation of resources was measured using the Polish adaptation of Hobfoll's Conservation of Resources Evaluation - Parts A and B, prepared by Dudek, Gruszczyńska, and Koniarek (2006). In Part A the task was to indicate the importance of resources on a fivepoint scale. In Part B, the participants were supposed to answer the questions already asked in Part A, but this time they were to indicate to what extent there had been a change for the worse (losses) and for the better (gains) over the previous year. Change for the better and for the worse was computed by multiplying the importance of a given resource (Part A score) by its change (Part B score). After adding up all the results, we obtained values for resource gains and, separately, values for resource losses. All the scales and questionnaires have high Cronbach's $\alpha$ reliability coefficients (> .80).

\section{PARTICIPANTS}

The participants examined were 83 patients with clinically diagnosed multiple sclerosis; 77 patients were qualified for the study, in order for the sample to be more homogeneous in terms of age. The age of the 77 participants ranged from 24 to $57(M=39.30$, $S D=8.67)$. Table 1 presents the participants' demographic data depending on time since diagnosis. Based on the temporal criterion - namely, time since diagnosis - we distinguished two groups: people suffering from the disease for four years or more and people diagnosed less than four years before.
Psychological profiles of patients with MS 
Table 1

Participants' demographic data depending on time since diagnosis

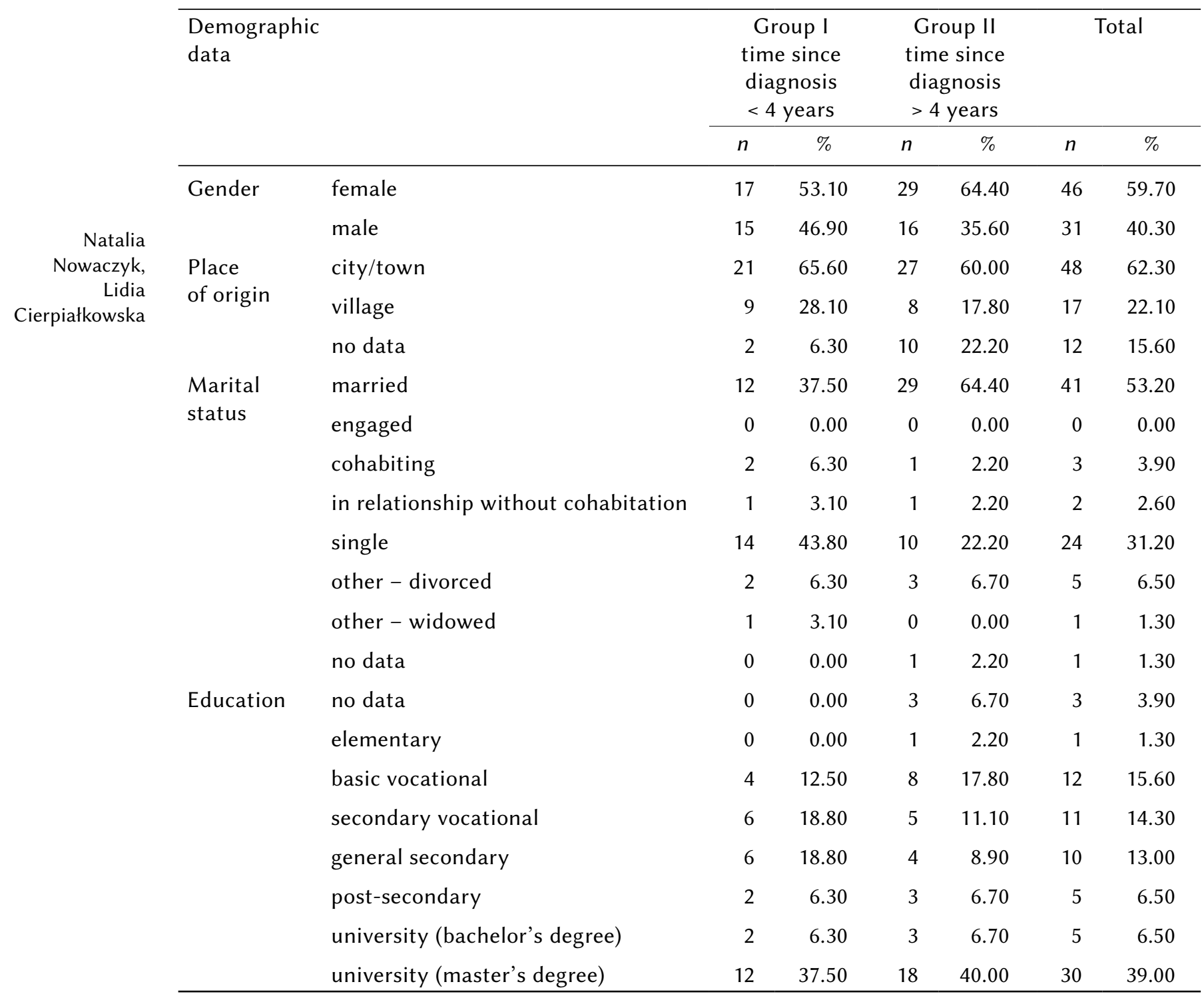

\section{STATISTICAL ANALYSES}

In order to determine the psychological profile of a given group of patients, we performed $k$-means clustering using SPSS 22. We determined the number of clusters using hierarchical cluster analysis. Next, by performing a one-way analysis of variance, we tested the significance of differences in the level of particular resources. In the case of a lack of normal distribution of results, we used the Kruskal-Wallis test.

\section{RESULTS}

\section{DESCRIPTIVE DATA}

The explained variable was the level of resource conservation, comprising resource gains $(M=373.00$, $S D=475.50)$ and losses $(M=192.00, S D=362.50)$ and the importance of resources $(M=385.00, S D=43.20)$ over a year. The explanatory variables were coping strategies, the experience of positive and negative feelings, depressive experiences, the sense of fatigue, and pain complaints.

\section{INFERENTIAL STATISTICS}

Based on $k$-means cluster analysis, we distinguished three profiles of patients with multiple sclerosis, which are presented in Figures 1 and 2.

Profile 1, characterized by the prevalence of resource losses over gains, covers the group of patients who observed mainly changes consisting in the diminishing of resources in various life domains due to the progressing illness, while observing changes for the better to a smaller extent. These people experienced losses in both individual and family resources. 


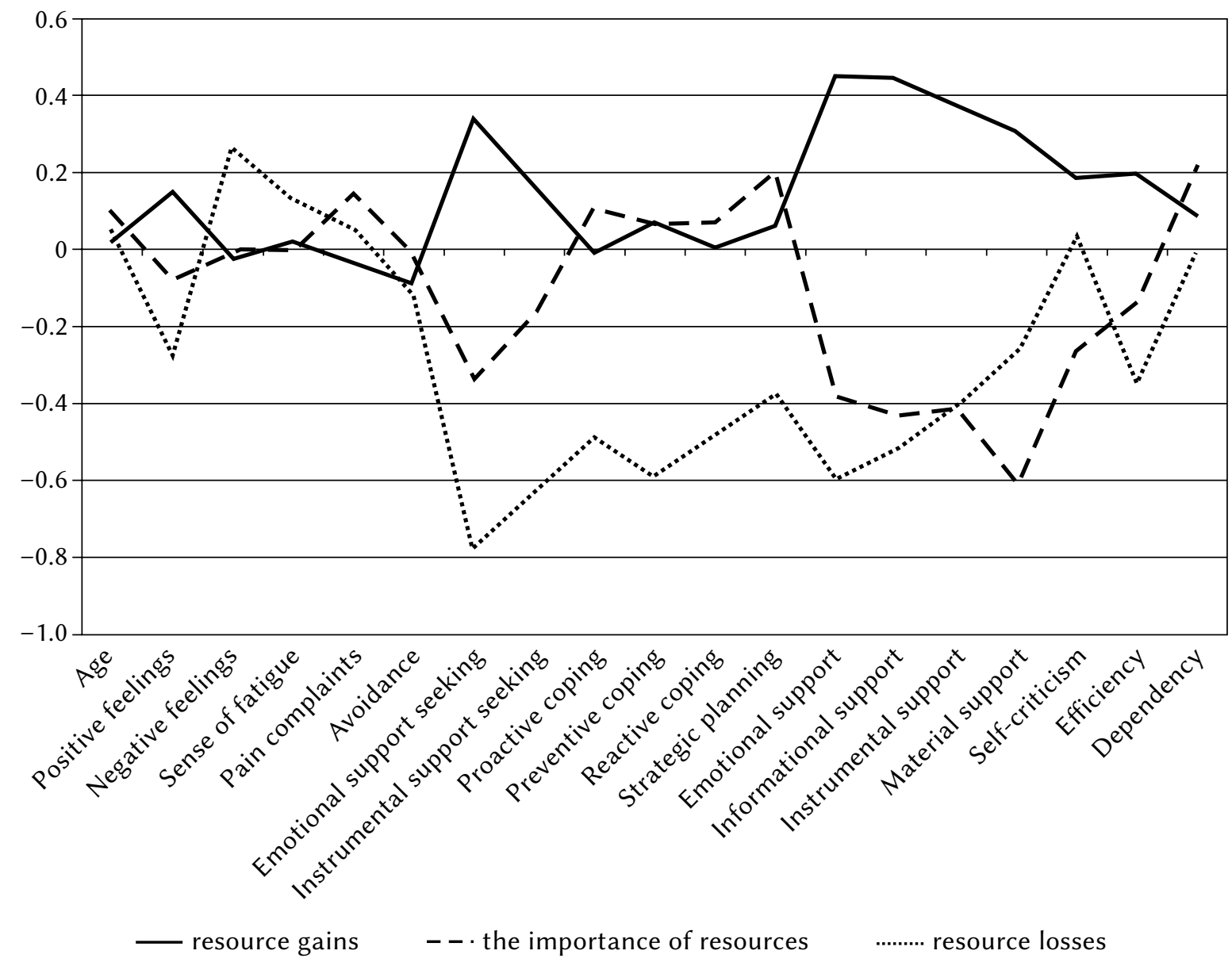

Psychological profiles of patients with MS

Figure 1. Profiles distinguished using $k$-means cluster analysis on cases according to personal and situational variables - the importance of resources, resource gains, and resource losses (means in standardized $z$ units).

As regards individual domains, they usually indicated losses in economic and political, power and prestige, vital, and spiritual resources. The profile was represented by 12 women and 18 men; 18 of these people had suffered from multiple sclerosis for more than four years, and 12 for less than four years. The group with Profile 1 experienced negative emotions more often and reported a stronger sense of fatigue and pain complaints than the groups with Profiles 2 and 3 . These people did not differ from individuals with Profiles 2 and 3 in terms of the frequency and intensity of depressive experiences.

Profile 2 was represented by the patients who rated the value of their resources the highest. They declared that all individual as well as family resources were very important to them and that during the previous year there had been neither losses nor gains in the resources possessed. This profile was represented by 19 women and 6 men; 17 of these people had suffered from the disease for more than four years and 8 people had been ill for less than four years. Compared to the group with Profile 1, the group with Profile 2 more often used diverse coping strategies, with preventive coping being used the most frequently. Because preventive coping relates to uncertain future life events, people representing Profile 2 adopted an attitude oriented towards accumulating new resources or maintaining those already possessed in order to minimize the effects of stressful events that may occur in the future (Heszen \& Sęk, 2007). Moreover, patients in this group were characterized by moderate subjectively perceived social support. These people did not differ from individuals representing Profiles 2 and 3 in the level of self-criticism, dependency or efficiency and the experience of positive feelings.

Profile 3 concerned patients who had gained more new resources over the previous year - particularly vital and spiritual resources. This probably stems from a change of the hierarchy of values and from adopting a reflective attitude, perhaps more oriented towards accepting the current situation than towards changing it. The profile was represented by 11 women and 7 men; 12 of these people had suffered from the disease for more than four years and the remaining 6 people had been ill for less than four years. The group with Profile 3 received instrumental, informational, material, and emotional social support and used the emotional support seeking strategy much more often than the groups with Profiles 1 and 2. These people did not differ from individuals representing Profiles 


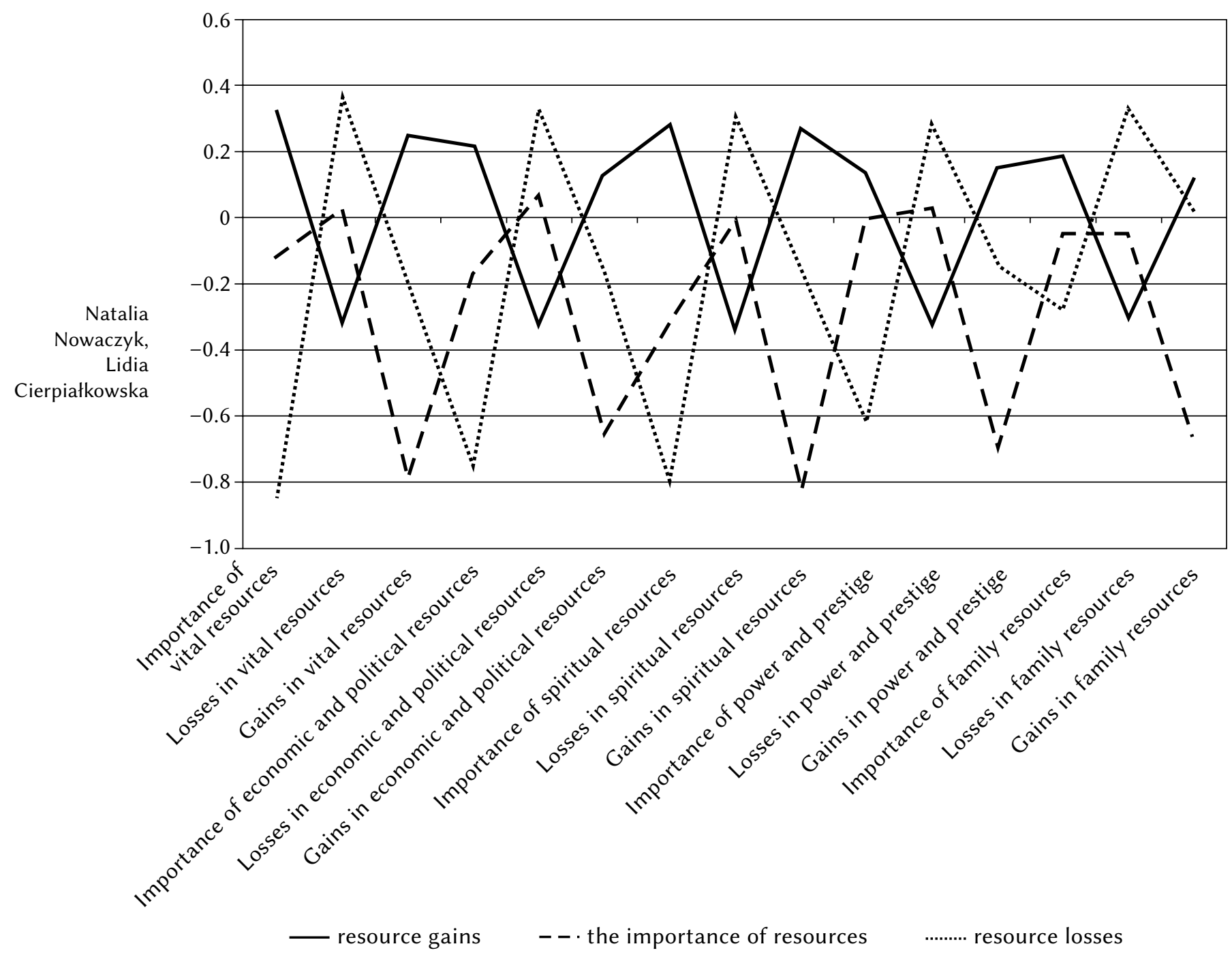

Figure 2. Profiles distinguished using $k$-means cluster analysis on cases according to conservation of resources - the importance of resources, resource gains, and resource losses (means in standardized z units).

1 and 3 in terms of depressive experiences and the experience of positive feelings.

Table 2 shows which variables statistically significantly differentiate the profiles of patients with multiple sclerosis.

The values obtained in the one-way analysis of variance indicate statistically significant differences between profiles of patients in terms of coping strategies, while the values obtained in the Kruskal-Wallis test point to statistically significant differences between patients' profiles in terms of subjectively perceived social support, coping strategies, and conservation of resources. We also tested the influence of controlled incidental variables using the $\chi^{2}$ test and found a statistically significant effect only for gender $(p=.044)$.

\section{CONCLUSIONS}

The results of the study made it possible to distinguish three profiles, which confirm the hypothesis about the diverse dynamics of resource conservation in patients. It was precisely the conservation of resources theory that turned out to be the key to the identification of the profiles of patients with multiple sclerosis. The results suggest that this situation is closely connected not only with the dynamics of resource conservation, but also with the occurrence of subjectively perceived social support as well as with the use of different coping strategies.

We observed that individuals achieving gains in resources were characterized by higher presence of subjectively perceived social support than the remaining groups (particularly compared to the group with a prevalence of resource losses). Moreover, in people with a prevalence of gains the coping strategy that turned out to be the most effective was emotional support seeking. Many studies show that this way of coping is more often used in patients with multiple sclerosis than instrumental coping, though it does not always prove to be more effective (McCabe, McKern, \& McDonald, 2004). Emotional sup- 
Table 2

Association of the variables with the three clusters $(N=73$, intergroup $d f=3$, intragroup $d f=70)$

\begin{tabular}{|c|c|c|c|c|c|}
\hline \multirow[t]{2}{*}{ Variables } & & Profile of people & & \multicolumn{2}{|c|}{$F$ test statistic } \\
\hline & \multicolumn{3}{|c|}{$M(S D)$} & $F$ & $p$ \\
\hline Positive feelings & $19.67(3.15)$ & $21.76(5.87)$ & $21.89(3.78)$ & 1.66 & .183 \\
\hline Negative feelings & $16.17(3.83)$ & $13.60(5.65)$ & $14.83(4.98)$ & 1.99 & .123 \\
\hline Emotional support seeking & $2.28(0.42)$ & $2.98(0.54)$ & $3.11(0.33)$ & 16.96 & $<.001$ \\
\hline Instrumental support seeking & $2.29(0.33)$ & $2.92(0.59)$ & $2.85(0.54)$ & 11.24 & $<.001$ \\
\hline Preventive coping & $2.39(0.47)$ & $3.04(0.36)$ & $2.70(0.46)$ & 11.26 & $<.001$ \\
\hline Reactive coping & $2.47(0.41)$ & $2.96(0.32)$ & $2.67(0.53)$ & 8.63 & $<.001$ \\
\hline Self-criticism & $72.47(18.31)$ & $65.52(22.04)$ & $81.22(22.97)$ & 1.99 & .123 \\
\hline Efficiency & $36.00(6.45)$ & $40.08(7.47)$ & $40.94(8.02)$ & 2.30 & .085 \\
\hline \multirow[t]{3}{*}{ Dependency } & $32.43(7.46)$ & $34.32(9.46)$ & $31.39(8.48)$ & 0.47 & .703 \\
\hline & & & & \multicolumn{2}{|c|}{$\chi^{2}$ test statistic } \\
\hline & & & & $\chi^{2}$ & $p$ \\
\hline Age & 39.00 & 37.62 & 36.56 & 2.26 & .520 \\
\hline Sense of fatigue & 39.50 & 34.80 & 37.39 & 0.85 & .837 \\
\hline Pain complaints & 39.23 & 38.88 & 33.33 & 1.28 & .733 \\
\hline Avoidance & 35.73 & 39.52 & 35.67 & 3.37 & $<.001$ \\
\hline Proactive coping & 26.27 & 51.42 & 34.86 & 21.91 & .339 \\
\hline Strategic planning & 29.25 & 48.96 & 33.86 & 13.88 & .003 \\
\hline Emotional support & 24.80 & 41.88 & 53.92 & 23.25 & $<.001$ \\
\hline Instrumental support & 26.17 & 38.20 & 55.75 & 21.45 & $<.001$ \\
\hline Informational support & 27.93 & 36.92 & 53.39 & 16.68 & .001 \\
\hline Material support & 32.85 & 30.38 & 54.75 & 16.48 & .001 \\
\hline Importance of vital resources & 18.32 & 53.26 & 45.86 & 42.32 & $<.001$ \\
\hline Losses in vital resources & 45.95 & 30.68 & 30.86 & 12.34 & .006 \\
\hline Gains in vital resources & 35.85 & 21.78 & 60.06 & 36.52 & $<.001$ \\
\hline $\begin{array}{l}\text { Importance of economic } \\
\text { and political resources }\end{array}$ & 21.37 & 49.32 & 46.08 & 29.84 & $<.001$ \\
\hline $\begin{array}{l}\text { Losses in economic and political } \\
\text { resources }\end{array}$ & 45.80 & 33.72 & 26.89 & 12.95 & .005 \\
\hline $\begin{array}{l}\text { Gains in economic and political } \\
\text { resources }\end{array}$ & 34.83 & 24.18 & 58.42 & 30.56 & $<.001$ \\
\hline $\begin{array}{l}\text { Importance of spiritual } \\
\text { resources }\end{array}$ & 19.18 & 49.96 & 49.03 & 37.52 & $<.001$ \\
\hline Losses in spiritual resources & 45.92 & 32.62 & 28.22 & 14.39 & .002 \\
\hline Gains in spiritual resources & 36.93 & 20.58 & 59.92 & 38.71 & $<.001$ \\
\hline $\begin{array}{l}\text { Importance of power and } \\
\text { prestige }\end{array}$ & 22.28 & 51.46 & 41.56 & 28.83 & $<.001$ \\
\hline
\end{tabular}

(Table 2 continues) 
Table 2

(Table 2 continued)

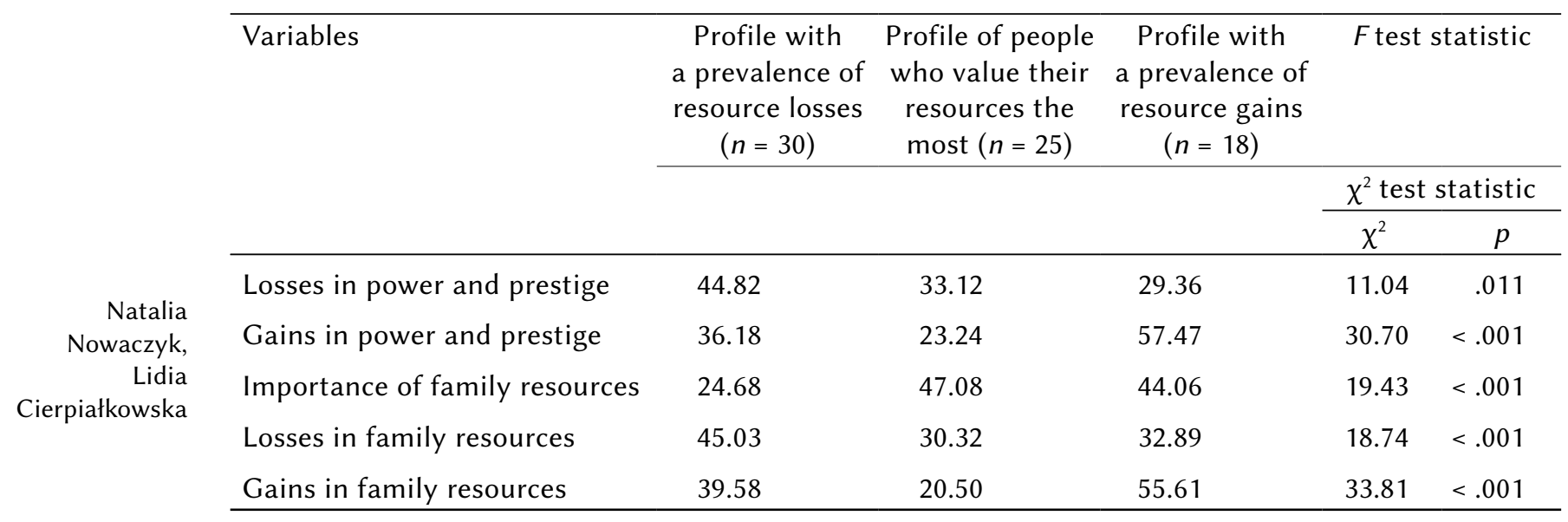

port seeking and subjectively perceived social support seem to be indicators of acquiring new resources or enhancing those already present (especially vital and spiritual resources), thus improving the quality of the patients' life.

A considerable role is also played by the participants' gender, which differentiates three psychological profiles of patients. The profile with a prevalence of loss in resources, where negative feelings dominate and where the sense of fatigue and pain complaints are stronger, mostly relates to men. Perhaps receiving information about multiple sclerosis diagnosis and/or an intensification of the symptoms of the disease is more difficult to accept and come to terms with for men because it is connected with the necessity of asking for more support and care, which men may not be willing to accept. The need for support and a strategy based on emotional support seeking is more often manifested by women, which is also associated with increasing the pool of resources. In the present study, a predominance of women was also found in the group of patients who value resources the most. When analyzing the characteristics of this profile, one can conclude that its representatives are resourceful people who try to maintain balance in different life domains, which may stem from the process of adaptation to the disease. Also other studies (Magyari, 2016) show a significant role of gender in coping with multiple sclerosis, though the study by Théaudin, Romero, and Feinstein (2016) revealed a higher presence of anxiety in women suffering from multiple sclerosis.

The profiles of patients with multiple sclerosis identified in the present study should be taken into account in the rehabilitation process as well as inspiring the improvement and expansion of multidisciplinary rehabilitation, which plays a very important therapeutic role (Khan, Turner-Stokes, Ng, \& Kilpatrick, 2007). Going further, based on the results obtained in the study, it is possible to formulate a few guidelines important for effective rehabilitation:

1. Psychological rehabilitation should take into account the dynamics of resource conservation: the importance of resources, resource gains, and resource losses.

2. It is worth remembering that various kinds of resources are important for patients: vital, spiritual, economic and political, power and prestige, and family resources; gains in vital and spiritual resources are associated with emotional support seeking and with receiving stronger social support.

3. Subjectively perceived social support is the strongest in people with a prevalence of resource gains and the weakest in people with a prevalence of resource losses.

4. A sense of fatigue and pain complaints is present in people with a prevalence of resource losses.

5. Gender significantly differentiates the psychological profiles obtained: resource losses are more often present in men, whereas resource gains and the recognition of the importance of resources are more often found in women.

6. Psychological rehabilitation should also take into account the use of different coping strategies by different groups of patients.

\section{References}

Gruszczyńska, E. (2012). Kwestionariusz samooceny zysków i strat - polska adaptacja COR-Evaluation S.E. Hobfolla i jej podstawowe właściwości psychometryczne [S.E. Hobfoll's Conservation of Resources Evaluation and its basic psychometric properties]. In E. Bielawska-Batorowicz \& B. Dudek (eds.), Teoria zachowania zasobów Stevana E. Hobfolla. Polskie doświadczenia [Stevan E. Hobfoll's conservation of resources theory: Polish experiences] (pp. 99-110). Łódź: Wydawnictwo Uniwersytetu Łódzkiego. 
Heszen, I., \& Sęk, H. (2007). Psychologia zdrowia [Health psychology]. Warszawa: Wydawnictwo Naukowe PWN.

Hobfoll, S. E. (2012). Teoria zachowania zasobów i jej implikacje dla problematyki stresu, zdrowia i odporności [Conservation of resources theory: Its implications for stress, health, and resilience]. In E. Bielawska-Batorowicz \& B. Dudek (eds.), Teoria zachowania zasobów Stevana E. Hobfolla. Polskie doświadczenia [Stevan E. Hobfoll's conservation of resources theory: Polish experiences] (pp. 17-42). Łódź: Wydawnictwo Uniwersytetu Łódzkiego.

Khan, F., Turner-Stokes, L., Ng, L., \& Kilpatrick, T. (2007). Multidisciplinary rehabilitation for adults with multiple sclerosis. Cochrane Database of Systematic Reviews, 18, 1-20.

Khan, F., McPhail, T., Brand, C., Turner-Stokes, L., \& Kilpatrick, T. (2006). Multiple sclerosis: Disability profile and quality of life in an Australian community cohort. International Journal of Rehabilitation Research, 29, 87-96.

Magyari, M. (2016). Gender differences in multiple sclerosis epidemiology and treatment response. Danish Medical Journal, 63, 1-18.

McCabe, M. P., McKern, S., \& McDonald, E. (2004). Coping and psychological adjustment among people with multiple sclerosis. Journal of Psychosomatic Research, 56, 355-361.

Milanlioglu, A., Özdemir, P. G., Cilingir, V., Gülec, T. Ç., Aydin, M. N., \& Tombul, T. (2014). Coping strategies and mood profiles in patients with multiple sclerosis. Arquivos de Neuro-Psiquiatria, 72, 490-495.

Nowaczyk, N., \& Cierpiałkowska, L. (2016, in press). Radzenie sobie ze stwardnieniem rozsianym z perspektywy koncepcji zachowania zasobów S.E. Hobfolla [Coping with multiple sclerosis from the perspective of S.E. Hobfoll's conservation of resources theory]. Postępy Psychiatrii i Neurologii.

Ožura, A., \& Sega, S. (2013). Profile of depression, experienced distress and capacity for coping with stress in multiple sclerosis patients - a different perspective. Clinical Neurology and Neurosurgery, $115,12-16$.

Schreiber, H., Lang, M., Kiltz, K., \& Lang, C. (2015). Is personality profile a relevant determinant of fatigue in multiple sclerosis? Frontiers in Neurology, $6,1-7$.

Théaudin, M., Romero, K., \& Feinstein, A. (2016). In multiple sclerosis anxiety, not depression, is related to gender. Multiple Sclerosis Journal, 22, 239-244. 